\title{
Planned surgical admissions in a district hospital
}

\author{
J A SOUTHAM, R W TALBOT
}

In 1976 it was decided to assess the feasibility of planned admissions in a general surgical unit in a busy district hospital. We wanted to find out how this would benefit patients and the unit.

\section{Method}

Epsom District Hospital, which has 527 beds, serves a population of about 172000 in the Mid-Surrey District. At the start of the trial the unit had 22 acute adult beds and a variable number of children's beds in the main hospital. There is a preconvalescent hospital seven miles away where a further four or five beds may be available. These are for patients who have had operations but who are not ready for early discharge. They are also used for patients who live alone or have difficult home conditions and require a period of convalescence and for people who are waiting for geriatric or terminal care accommodation.

In the outpatient department the consultant sees most patients who are referred to him specifically and the registrar examines the rest. After any necessary investigations have been carried out the patients who require admission for operation are listed. They are told that they will receive a letter within a week giving them the date when they are to come into hospital. They are asked if there are any periods that would be inconvenient or whether any would be particularly helpful to them. With the admission letter they receive a brochure about the hospital and a form, which they are required to sign and return to the secretary, stating that they agree to the date proposed. One paragraph states that if there is a sudden increase in the number of emergencies resulting in acute pressure on the beds they will be contacted and given an alternative date.

All the names, with the type of operation, are entered in a special diary, first in pencil. When an acceptance is received these details are confirmed in ink. Also included are details of day cases and of early admissions for bowel or thyroid preparation and for special investigations or blood transfusions. Patients normally come in on the morning of the day before their operation. Everybody seen in the outpatient department is given an advance booking, except those requiring surgery on varicose veins or wanting a vasectomy. These are kept as a "float," to be sent for if there are any gaps.

There are four morning operating lists a week in the main hospital, each lasting about four hours. Two are carried out by the consultant and two by the registrar. The cases treated in the cottage hospitals have not been included in the survey. On a Tuesday morning the consultant and the registrar each have a list in adjacent theatres assisted by a house surgeon and a senior house officer. This permits some flexibility in allowing patients to be switched from one list to another should either be running late. On Thursday the more complicated or interesting cases are operated on. As it is a combined list the whole team is present and instruction can be given to the registrar. The final list is on the following day and acts as a form of "sweeper." It contains a few elective cases but there is operating time available for

Epsom District Hospital, Epsom, Surrey KT18 7EG

J A SOUTHAM, MB, FRCs, consultant surgeon

St James's Hospital, Balham, London SW12 8HW

R W TALBOT, MB, FRCs, surgical registrar patients admitted as emergencies during the week who are subsequently found to require surgery. The changeover period started on 1 October 1976. During the next three months none of the new patients seen were given bookings until after 1 January 1977. By then most of the patients already on the waiting list had had their operation.

\section{Results}

Table I summarises the overall activity of the unit during the four years studied. 1976 has been excluded as it was in the changeover period. During the two years of planned admissions there was a substantial increase in the number of new patients attending the outpatient clinic. The total number of discharges

TABLE I-Activity in the unit

\begin{tabular}{lrrrrrrr}
\hline & & & 1974 & 1975 & 1977 & 1978 \\
\hline New outpatient attendances & $\ldots$ & $\ldots$ & 888 & 711 & 1025 & 1078 \\
Total discharges & $\ldots$ & $\ldots$ & $\ldots$ & 1144 & 1328 & 1629 & 1523 \\
Emergency admissions & $\ldots$ & $\ldots$ & $\ldots$ & 531 & 514 & 539 & 512 \\
Elective admissions & $\because$ & $\ldots$ & $\ldots$ & 589 & 781 & 1059 & 996 \\
Percentage of elective admissions & & $\ldots$ & $51 \cdot 6 \%$ & $58.8 \%$ & $71 \cdot 2 \%$ & $65.0 \%$ \\
Average bed occupancy & $\ldots$ & $\ldots$ & $\ldots$ & 33 & 31 & 31 & 28 \\
Average stay (days) & $\ldots$ & $\ldots$ & $\ldots$ & 11 & 11 & $8 \cdot 5$ & $8 \cdot 2$
\end{tabular}

from the hospital went up but the emergency admissions remained constant. Admissions for elective surgery increased by about half in the planned years compared with the unplanned. The bed occupancy dropped in 1978 owing to the closure of four acute adult beds, the result of a shortage of nursing staff. The average length of stay in hospital, however, fell and so compensated for this.

Table II shows the percentages of the various grades of operation carried out; there is little difference between the two

TABLE II-Type of operation

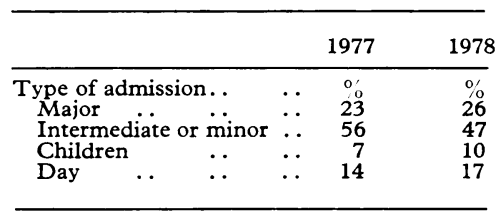

years. Table III shows the waiting times for several types of operation, which gradually became shorter. It did not, however, change for urgent cases, such as carcinoma or benign lumps of the breast.

\section{Discussion}

At first the idea of planning surgical admissions many months in advance seemed a daunting task. The two main problems were to plan within the confines of a fixed number of beds and to prevent operating lists from running over their permitted time. In addition, changes of registrars and holidays had to be allowed 
for. Practice gradually improved the technique and there was a drop in cancellations during 1978-20. The number has again been reduced in 1979. Of the 63 patients whose operations were cancelled in 1977, 55 were during the first six months of the year. The main reason for this was the prolonged industrial action that affected the hospital during part of this time.

There are several factors that help the system to run effectively. Firstly, having all the adult patients in one mixed ward is a great advantage, particularly when this is subdivided into single rooms and four- and six-bedded units. This allows considerable nurse and readmission because of subsequent complications has been uncommon. The general practitioner can tick a square on the referral letter if he is willing to accept the patient for an early discharge.

As expected, the scheme has proved to be of enormous benefit to the patients. Almost everyone has a fear of operations, particularly the first. An expected admission date is much more acceptable than a nebulous one at some unknown time in the future. Children are generally admitted during the holidays so that they do not have time off school. A prearranged date is

TABLE III-Average waiting time in days for various operations

\begin{tabular}{|c|c|c|c|c|c|c|c|c|c|c|c|}
\hline & & & \multicolumn{3}{|c|}{1974} & \multicolumn{2}{|c|}{1975} & \multicolumn{2}{|c|}{1977} & \multicolumn{2}{|c|}{1978} \\
\hline & & & & $\begin{array}{c}\text { No } \\
\text { admitted }\end{array}$ & $\begin{array}{c}\text { Waiting } \\
\text { time }\end{array}$ & $\begin{array}{c}\text { No } \\
\text { admitted }\end{array}$ & $\begin{array}{c}\text { Waiting } \\
\text { time }\end{array}$ & $\begin{array}{c}\text { No } \\
\text { admitted }\end{array}$ & $\underset{\text { time }}{\text { Waiting }}$ & $\begin{array}{c}\text { No } \\
\text { admitted }\end{array}$ & $\begin{array}{c}\text { Waiting } \\
\text { time }\end{array}$ \\
\hline $\begin{array}{l}\text { Average for all operations } \\
\text { Hernias }\end{array}$ & $\begin{array}{l}\because \\
\therefore \\
\cdots \\
\cdots \\
\cdots\end{array}$ & $\begin{array}{l}. \\
\cdots \\
\cdots \\
\cdots \\
\cdots\end{array}$ & $\begin{array}{l}\cdots \\
\cdots \\
\cdots \\
\cdots \\
\cdots\end{array}$ & $\begin{array}{l}60 \\
39 \\
13 \\
43 \\
41 \\
21\end{array}$ & $\begin{array}{r}85 \\
157 \\
116 \\
153 \\
90 \\
24 \\
12\end{array}$ & $\begin{array}{r}42 \\
30 \\
9 \\
29 \\
53 \\
28\end{array}$ & $\begin{array}{r}96 \\
219 \\
104 \\
93 \\
139 \\
13 \\
12\end{array}$ & $\begin{array}{r}100 \\
68 \\
17 \\
42 \\
59 \\
25\end{array}$ & $\begin{array}{r}113 \\
133 \\
87 \\
71 \\
78 \\
19 \\
10\end{array}$ & $\begin{array}{l}66 \\
43 \\
18 \\
42 \\
48 \\
24\end{array}$ & $\begin{array}{l}95 \\
77 \\
81 \\
59 \\
51 \\
20 \\
11\end{array}$ \\
\hline
\end{tabular}

versatility, as men and women can be admitted into any of the sections and subsequently moved around, depending on the demand at the time. The common room, toilets, and bathrooms are shared and, as they are built on the "race track" system, there have never been any problems or complaints.

Secondly, whenever possible discharges are arranged in advance to coincide with the new admissions and to leave empty beds available for emergencies. The co-operation of the nursing staff is vital in making this system work efficiently. "Lodgers" from other wards are readily accepted, provided that they are taken back when the beds are required. This is important as it provides the good will that is necessary for borrowing beds if too many patients have been sent for. The imponderable must always be the number of emergency patients who are admitted during the one in three "take" days and again beds have had to be borrowed occasionally.

\section{IMPORTANCE OF MIXTURE}

The spacing out of the operating sessions through the week is important. This enables day- and short-stay patients to be treated and discharged, allowing further patients to come in for subsequent lists. To achieve this every operating list has a variety of cases. Avery Jones and $\mathrm{McCarthy}{ }^{1}$ emphasise that a manageable surgical waiting list is desirable for the efficient use of theatres, with a suitable mixture of major and minor operations.

When planning admissions sufficient slots should be available for the urgent admission of patients with malignant diseases. As soon as an elderly person is admitted the social worker is contacted to prepare a report on the home circumstances. This means that problems regarding discharge from hospital are anticipated well in advance and appropriate plans made. This is why the preconvalescent hospital-at present threatened with closure-is so valuable.

In places with long average waiting times Rudge and Richards ${ }^{2}$ showed that demand rates would be likely to increase if these waiting times were reduced. The idea of planning admissions was not advertised, nor were the general practitioners told about it in advance in case it failed to work. Its popularity is shown by the increase in the number of patients referred to the outpatient department. As a result the waiting time from referral to appointment has increased from three to five weeks.

Early discharge from hospital appealed to most of the patients and it subsequently became essential when four adult beds in the unit were lost. Stitches are removed by the district invaluable to the man with business commitments, and women with families can plan for their children to be looked after while they are away from home.

\section{TAKEN FOR GRANTED BY PATIENTS}

Surprisingly, however, so far not a single patient has expressed any appreciation of the system; they have apparently taken it for granted.

By becoming more aware of its bed occupancy and requirements, the surgical unit has also gained considerably from this method. Everyone knows well in advance exactly how many patients are coming in on any particular day. Almost every patient really does arrive at the hospital on the right day. This prevents unnecessary empty beds and waste of operating time. With the usual system, where the patient is sent a letter the week before admission, he frequently fails to turn up. The reasons are numerous: for example, the letter fails to arrive, the patient is away, or the time is inconvenient because of work or family commitments. This is shown by the fact that from March to August 1978 only one out of 350 admissions was cancelled at short notice. In contrast, on another firm during the same period 25 out of 250 patients cancelled and 20 of these were due to come in during the school holiday period. In the surgical unit there were five cancellations by patients in 1977 and four in 1978.

There is no extra cost in running the system, no extra secretarial help is needed, and it requires no more time than the more traditional methods used for admitting patients. With good organisation the system of planned admissions for surgical cases can be carried out in any general hospital. Where resources in the NHS are rapidly becoming more restricted it ensures the best use of available beds and theatre time with an increased throughput of patients. The waiting time for operations was not significantly reduced but it has at least been contained at a time when waiting lists throughout the country have grown considerably.

\section{References}

1 Avery Jones F, McCarthy M. Understanding waiting lists. Lancet 1978; ii:34-6.

2 Rudge JF, Richards BW. Strategic planning of acute beds by specialty. Br Med f 1979;ii:1240-2. 